\title{
O PAPEL DAS ESTRUTURAS INTERMÉDIAS NA INCLUSÃO DOS ALUNOS COM NECESSIDADES EDUCATIVAS ESPECIAIS NO ENSINO SECUNDÁRIO
}

\author{
Cristina Rocha Matos ${ }^{l}$ \\ João Esteves Salgueiro ${ }^{2}$
}

\begin{abstract}
Resumo: $O$ presente trabalho tem como objetivo divulgar os resultados de um estudo empírico levado a cabo no Agrupamento de Escolas do Sátão, onde funciona uma Unidade de Multideficiência e Surdo Cegueira Congénita, no sentido de percecionar o papel desempenhado pelas estruturas de gestão intermédia na inclusão dos alunos com Necessidades Educativas Especiais (NEE) no ensino secundário. $O$ alargamento da escolaridade obrigatória para doze anos levou-nos a questionar a forma como as lideranças intermédias estariam a preparar a chegada destes alunos às escolas do ensino secundário e, nesse sentido, efetuámos uma investigação qualitativa, de tipo descritivo, baseada na entrevista e com recurso à análise documental. Dos resultados obtidos salientamos a posição das lideranças que defenderam a inclusão parcial (se e quando houver condições por parte das escolas). Embora demonstrando consciência da importância do seu papel no sucesso educativo dos alunos com NEE, reconhecem a sua falta de iniciativa junto da comunidade educativa, no sentido de desenvolverem as ações necessárias para a obtenção desse sucesso.
\end{abstract}

Palavras-chave: Estruturas intermédias, lideranças intermédias; escolaridade obrigatória; NEE; inclusão.

Abstract: This article aims to disseminate the results of an empirical study carried out in the Sátão Grouping of Schools, where works a unit for multi Congenital Blindness and Deaf, to percept the

\footnotetext{
${ }^{1}$ Professora do $3 .^{\circ}$ ciclo e ensino secundário no Agrupamento de Escolas de Sátão, Mestre em Ciências da Educação, Educação Especial - Domínio Cognitivo e Motor (crisroch@iol.pt)

${ }^{2}$ Professor do $3^{\circ}$ ciclo e ensino secundário no Agrupamento de Escolas de Viseu Norte, Mestre em Ciências de Educação - Educação e Currículo (joaoesalgueiro@gmail.com)
} 


\section{Cristina Rocha Matos e João Esteves Salgueiro}

role of middle management structures in the inclusion of students with Special Educational Needs (SEN) in secondary education. The extension of compulsory education to twelve years has led us to question how the middle leadership would be preparing the arrival of these students at secondary schools and, accordingly, we conducted a qualitative investigation, descriptive type, based on interviews and use of document analysis. From the results we highlight the position of leadership who advocated the partial inclusion (if and when conditions exist on schools). Although they demonstrate awareness of the importance of their role in the educational success of students with SEN, they recognize their lack of initiative within the educational community to develop the necessary actions to achieve this success.

Keywords: Intermediate structures, middle leadership; compulsory education; SEN; inclusion.

\section{INTRODUÇÃO}

O alargamento da escolaridade obrigatória para doze anos, a todos os alunos, incluindo aqueles com Necessidades Educativas Especiais (NEE), promovido pela Lei n. ${ }^{\circ} 85 / 2009$, de 27 de agosto, encaminhou para a escola secundária um grupo de alunos que, por norma, dela estavam afastados. Escola, essa, que, desde a publicação do Decreto-Lei n. ${ }^{\circ} 75 /$ 2008, de 22 de abril, alterado pelo Decreto-Lei n. ${ }^{\circ}$ 137/ 2012, de 2 de julho, introduziu um modelo de administração e gestão unipessoal, centrado na figura do Diretor, coadjuvado por uma equipa de direção e cujo governo é favorecido pelo contributo das estruturas de coordenação, ou seja, as lideranças intermédias. Estas, pelo seu posicionamento entre o topo e a base, terão, certamente, uma palavra a dizer na inclusão dos alunos com NEE neste nível de ensino.

A nossa investigação, sob o título, "o papel das estruturas de gestão intermédia na inclusão dos alunos com NEE no ensino secundário", foi realizada no Agrupamento de Escolas de Sátão que acedeu, amavelmente, ao pedido de análise de documentos oficiais, permitiu a realização de entrevistas e a divulgação do estudo, com identificação do local onde o mesmo foi efetuado. Este Agrupamento de escolas tem em funcionamento uma Unidade de Multideficiência e Surdo Cegueira Congénita. O estudo foi realizado ao longo do ano letivo de 2011/2012, que precedeu a entrada compulsiva dos primeiros alunos abrangidos pelo Decreto-Lei n. ${ }^{\circ} 75 / 2009$, de 27 de agosto, no $10 .^{\circ}$ ano.

A opção por esta temática prende-se com a nossa atividade profissional e com os nossos interesses pessoais na área, assim como com a atualidade do assunto. Após uma exaustiva revisão bibliográfica, pudemos constatar que este era um território por explorar, pois esta 
temática não tinha ainda merecido a atenção dos investigadores. Isto, apesar da variedade de pesquisas efetuadas no campo da organização e administração escolar, das NEE e da inclusão.

A nossa opção metodológica assentou na realização de uma investigação qualitativa de tipo descritivo, usando como método privilegiado de colheita de dados a entrevista semiestruturada e a análise documental.

\section{A ESCOLA E A INCLUSÃO}

\subsection{Uma abordagem metafórica da organização educativa}

Relacionar a organização educativa com a inclusão pode, facilmente, tornar-se numa tarefa ingrata e embaraçosa. A organização escolar foi e continua a ser pensada e estruturada para o aluno padrão, pelo que, encarada sob o ponto de vista da inclusão, ela configura, sempre, uma visão artificial e forçada. Embora procure adaptar-se a este público, 'nãoalvo', não se revê nele. Foi 'forçada' a aceitá-lo e a inclúí-lo nos seus objetivos, mas não se recriou para o fundir com o público-alvo a que originariamente se destinou.

De acordo com Libâneo (2001), a organização escolar pode ser vista através de um enfoque crítico, de cunho sociopolítico, e de um enfoque científico-racional. No enfoque crítico, a escola acaba por se tornar uma "construção social levada a efeito pelos professores, alunos, pais e integrantes da comunidade próxima" (p. 97), ressalvando o seu interesse público. Olhada através de um enfoque científico-racional, a escola, é uma "realidade objetiva, neutra, técnica, que funciona racionalmente" e que pode ser "planeada, organizada e controlada, de modo a alcançar maiores índices de eficácia e eficiência" (idem).

O que atualmente parece estar a acontecer na organização escolar é que este enfoque científico-racional está a tomar proporções assustadoras e a assumir-se como visão única e limitativa da escola. Parece ser o auge da "educação contábil" (Lima, 2005, p.72), assumida pela comunidade educativa e por uma sociedade que, como tudo parece indicar, cada vez mais se revê nos rankings e aceita, de braços abertos, a economia de mercado aplicada à realidade escolar.

Numa organização pensada para outros, com um ethos de mercado e onde apenas os resultados académicos são válidos, os alunos com NEE só podem estar no caminho do insucesso e da exclusão.

Assim, para procurarmos entender melhor o que poderá estar a acontecer na escola, mobilizámos um quadro de análise devedor da teoria organizacional e recorremos à figura da metáfora, entendida como "uma 


\section{Cristina Rocha Matos e João Esteves Salgueiro}

força primária através da qual os seres humanos criam significados usando um elemento da sua experiência para entender outro" (Morgan, 2006, p. 21). Através dela, criamos imagens que nos permitem aceder a conteúdos mais complexos, utilizando para isso, conceitos que fazem parte do nosso quotidiano. Morgan (2006) considera que o uso individual da metáfora permite apenas uma visão unilateral, incompleta, parcial, enganosa e limitativa da realidade organizacional. Aconselha, por isso, o uso conjugado de múltiplas metáforas, a fim de nos proporcionar uma perspetiva abrangente da realidade, possibilitando várias interpretações e perspetivas que se complementam e que permitem uma ação direta na vida da organização.

O referido autor explora oito metáforas aplicadas às organizações e que nós sistematizámos no Quadro I.

\section{Quadro I}

As metáforas aplicadas às organizações e respetivas teorias, segundo Morgan

\begin{tabular}{|c|c|c|}
\hline Metáfora & Organizações & Teorias \\
\hline \multirow{2}{*}{ Máquinas } & \multirow{2}{*}{ Burocráticas } & - Administração clássica \\
\hline & & - Administração científica \\
\hline \multirow{2}{*}{ Organismos } & \multirow{2}{*}{ Sistemas abertos } & - Contingencial \\
\hline & & - Ecologia Populacional \\
\hline \multirow{3}{*}{ Cérebros } & \multirow{3}{*}{$\begin{array}{l}\text { Organizações que } \\
\text { aprendem }\end{array}$} & $\begin{array}{l}\text { - Cérebros Processadores de } \\
\text { Informação }\end{array}$ \\
\hline & & $\begin{array}{l}\text { - Sistemas Complexos } \\
\text { Capazes de Aprender }\end{array}$ \\
\hline & & - Sistemas Holográficos \\
\hline Culturas & Fenómenos Culturais & - Mini sociedades \\
\hline \multirow{2}{*}{$\begin{array}{l}\text { Sistemas } \\
\text { políticos }\end{array}$} & \multirow[b]{2}{*}{ Processos políticos } & - Sistemas de governo \\
\hline & & $\begin{array}{l}\text { - Sistemas de atividade } \\
\text { política }\end{array}$ \\
\hline \multirow{2}{*}{$\begin{array}{l}\text { Prisões } \\
\text { psíquicas }\end{array}$} & \multirow{2}{*}{$\begin{array}{l}\text { Sistemas prisioneiros } \\
\text { dos seus pensamentos e } \\
\text { ações }\end{array}$} & $\begin{array}{l}\text { - Armadilha do modo de } \\
\text { pensar aprovado }\end{array}$ \\
\hline & & $\begin{array}{l}\text { - Organização e o } \\
\text { inconsciente }\end{array}$ \\
\hline
\end{tabular}




\section{Quadro I}

(continuação)

\begin{tabular}{|c|c|c|}
\hline Metáfora & Organizações & Teorias \\
\hline \multirow{4}{*}{$\begin{array}{l}\text { Fluxo e } \\
\text { transformação }\end{array}$} & \multirow{4}{*}{$\begin{array}{l}\text { Expressões de } \\
\text { processos mais } \\
\text { profundos de } \\
\text { transformação e } \\
\text { mudança }\end{array}$} & - Autopoiese \\
\hline & & - Caos e da Complexidade \\
\hline & & $\begin{array}{l}\text { - Lógica da Causalidade } \\
\text { Mútua }\end{array}$ \\
\hline & & $\begin{array}{l}\text { - Lógica da Mudança } \\
\text { Dialética }\end{array}$ \\
\hline $\begin{array}{l}\text { Instrumentos de } \\
\text { dominação }\end{array}$ & $\begin{array}{l}\text { Sistemas que exploram } \\
\text { os seus empregados, o } \\
\text { ambiente natural e a } \\
\text { economia global }\end{array}$ & $\begin{array}{l}\text { - Teoria organizacional } \\
\text { radical }\end{array}$ \\
\hline
\end{tabular}

Quadro de elaboração própria

Muitas outras metáforas foram construídas, todas elas válidas e que poderão, de alguma forma, contribuir para a nossa própria visão da organização. Podemos, também, fazer uma leitura organizacional da escola, local onde várias metáforas coexistem e se entrecruzam, evidenciando, uma ou outra, em diferentes momentos.

Costa (1996) aplicou à escola seis metáforas cujas características facilmente reconhecemos em cada uma das nossas escolas e agrupamentos (Quadro II).

\section{Quadro II}

Imagens organizacionais da escola e respetivas características, segundo Costa (2006)

\begin{tabular}{|c|c|}
\hline $\begin{array}{c}\text { Imagens } \\
\text { organizacionais } \\
\text { da escola } \\
\end{array}$ & Características da escola \\
\hline $\begin{array}{c}\text { Empresa } \\
\text { (Henry Taylor) }\end{array}$ & $\begin{array}{l}\text { - Uniformidade curricular; de horários; organização } \\
\text { dos espaços educativos; } \\
\text { - Metodologias dirigidas para o ensino coletivo; } \\
\text { - Direção unipessoal; } \\
\text { - . . }\end{array}$ \\
\hline $\begin{array}{l}\text { Burocracia } \\
\text { (Max Weber) }\end{array}$ & $\begin{array}{l}\text { - Legalismo / Centralismo / Formalismo / Rotina / } \\
\text { Hierarquia / Impessoalidade; } \\
\text { - Recusa da diversidade e da heterogeneidade; } \\
\text { uniformidade; } \\
\text { - Seleção e preparação das elites; } \\
\text { - . . }\end{array}$ \\
\hline
\end{tabular}


Quadro II

(continuação)

\begin{tabular}{|c|c|}
\hline $\begin{array}{c}\text { Imagens } \\
\text { organizacionais } \\
\text { da escola }\end{array}$ & Características da escola \\
\hline $\begin{array}{c}\text { Democracia } \\
\text { (Elton May e John } \\
\text { Dewey) }\end{array}$ & $\begin{array}{l}\text { - Escola ao serviço da comunidade; escola como } \\
\text { comunidade educativa; } \\
\text { - Participação de pais, alunos, professores e sociedade; } \\
\text { - Implica autonomia; }\end{array}$ \\
\hline $\begin{array}{c}\text { Arena Política } \\
\text { (Victor Baldridge) }\end{array}$ & $\begin{array}{l}\text { - Colisão entre a legitimidade formal e informal; } \\
\text { - Existência de grupos departamentais que perseguem } \\
\text { interesses comuns, antagónicos; } \\
\text { - Conflitos decorrentes da tomada de decisões; } \\
\text { - . . }\end{array}$ \\
\hline $\begin{array}{c}\text { Anarquia } \\
\text { (Michael Cohen) }\end{array}$ & $\begin{array}{l}\text { - A escola é uma realidade complexa, heterogénea, } \\
\text { problemática e ambígua, } \\
\text { - Uma escola é uma sobreposição de diversos órgãos, } \\
\text { estruturas, processos ou indivíduos frouxamente } \\
\text { unidos e fragmentados. } \\
\text { - A organização escolas é vulnerável relativamente ao } \\
\text { seu ambiente externo que, sendo turbulento e incerto } \\
\text { aumenta a incerteza e a ambiguidade } \\
\text { organizacionais; } \\
\text { - ... }\end{array}$ \\
\hline $\begin{array}{c}\text { Cultura } \\
\text { (William Ouchi) }\end{array}$ & $\begin{array}{l}\text { - A escola é diferente das outras organizações e cada } \\
\text { escola é diferente de qualquer outra; } \\
\text { - Diversas manifestações simbólicas (como valores, } \\
\text { crenças, linguagem, rituais, cerimónias); } \\
\text { - A escola é uma mini sociedade; } \\
\text { - . . }\end{array}$ \\
\hline
\end{tabular}

Quadro de elaboração própria

\subsection{Liderança intermédia}

$\mathrm{Na}$ organização escolar encontramos gestores, cuja autoridade reside nos cargos formais que desempenham, e líderes que influenciam pessoas, independentemente de ocuparem ou não, um cargo.

Bateman e Snell (2008) distinguem três níveis organizacionais: gestão de topo (gestores estratégicos - o Diretor), gestão intermédia (gestores táticos - as estruturas de coordenação) e gestão de primeira linha (gestores operacionais - todos os professores). Os mesmos autores reforçam a importância dos gestores táticos ao afirmarem que "bons 
gestores intermédios fornecem as competências operacionais e a resolução de problemas práticos que mantêm a empresa a funcionar" (p. 23). Estes autores enunciam ainda, três tipos de competências, entendidas como "habilidades específicas que resultam do conhecimento, da informação, da prática e da aptidão" (p. 25) e que todos os gestores devem ter: competências técnicas, competências interpessoais e competências conceptuais e decisórias. Destas, apenas as competências interpessoais e de comunicação são importantes durante toda a carreira, possibilitando o desenvolvimento de uma relação de liderança sobre pessoas, relativamente às quais, não se exerce qualquer tipo de autoridade.

A liderança é definida por Northouse (2010) como "um processo pelo qual um indivíduo influencia um grupo de indivíduos para atingir um objetivo comum" (p. 3). Desta forma, a liderança é assumida, não como um traço ou característica inerente ao líder, mas como algo acessível a todos. Liderar é, de acordo com Radcliffe (2010), "uma atividade humana natural que faz parte de cada um de nós. Não é preciso um certo QI ou cargo para ser um líder" (p. 3). Estas noções seguem as tendências das teorias pós-modernas de liderança que, contrariamente às teorias clássicas, consideram que, a liderança, pode ser ensinada e aprendida. A par destas teorias podemos também encontrar variadíssimos estilos de liderança. Uma das perspetivas mais conhecidas é a dos três estilos de liderança: autoritário, liberal e democrático. Contudo, devemos considerar ilusória a procura da única ou melhor forma de liderança, "o desafio (...) é saber quando aplicar qual estilo, com quem e em que circunstâncias e atividades" (Chiavenato, 2004 p.125).

A importância da liderança intermédia é cada vez mais reconhecida, Maxwell (2011) afirma que " $99 \%$ da liderança ocorre não do topo mas do meio da organização" (p. 1) e, no caso da escola, o líder intermédio é o professor, que atua enquanto líder e membro da equipa, assumindo, assim, de acordo com Blanford (2006), um "papel híbrido" (p. 5).

Estes líderes intermédios poderão desempenhar um papel fundamental em prol da inclusão e do sucesso educativo dos alunos com NEE, uma vez que desenvolvem "o conhecimento e a compreensão, as competências e aptidões dos colegas" (Blanford, 2006, p. 4). Ao mesmo tempo, e devido à sua posição, eles são "os construtores da pirâmide humana, trabalhando em conjunto para construir uma plataforma sólida que alcance o topo e a base. Desafiam as expectativas, providenciam apoio para os outros e revelam elevados níveis de interdependência" (Smith, 2011, p. 5). Para além disso, divulgam junto dos gestores de primeira linha a visão de inclusão do gestor estratégico e fornecem apoio e orientação aos colegas, estimulando-os a ser profissionais de alto 


\section{Cristina Rocha Matos e João Esteves Salgueiro}

desempenho, coordenando os recursos existentes e tomando a iniciativa, junto da comunidade educativa e da comunidade envolvente, no sentido de proporcionarem aos alunos com NEE as condições para um ensino de qualidade, que respeite a diferença e satisfaça as necessidades a que têm direito.

\subsection{A organização escolar em Portugal}

\section{Modelo de gestão e de organização da escola}

Após a entrada em vigor do Decreto-lei $\mathrm{n}^{\circ} 75 / 2008$, de 22 de abril, a escola tem vindo a passar por alterações profundas, subordinada ao novo regime jurídico de autonomia, administração e gestão, e que transformou um modelo colegial e democrático num modelo unipessoal e profissionalizado. O poder formal é reforçado, sob a autoridade de um Diretor que tem o governo das áreas cultural, administrativa, financeira e pedagógica e que assume, por inerência, a presidência do Conselho Pedagógico. Designa a sua equipa de trabalho, nomeia um conjunto de coordenadores de estruturas intermédias, embora, mais recentemente, tenha passado apenas a condicionar a eleição dos Coordenadores de Departamento pelos professores (Decreto-Lei n. ${ }^{\circ}$ 137/2012, de 2 de julho). Tal concentração de poder, nas mãos de uma única pessoa, contraria alguns dos mais recentes estudos na área da liderança e da gestão que fazem a apologia de uma gestão democrática, colaborativa e partilhada (English, 2006, p. 566).

A par do Diretor é criado o Conselho Geral, órgão colegial de direção e principal estrutura de administração e gestão das escolas, com o objetivo de reforçar a participação das famílias e comunidades na direção estratégica dos estabelecimentos de ensino.

Se na organização escolar, que lidera, o Diretor, tem um poder demasiado extenso, a verdade é que ele próprio está na dependência da administração educativa tendo o dever, explícito, de cumprir e fazer cumprir as orientações emanadas da tutela e mantê-la permanentemente informada sobre todas as questões relevantes ao serviço (Decreto-Lei n. ${ }^{\circ}$ 75/2008, de 22 de abril, art. ${ }^{\circ} 29$, alíneas a) e b)). Ao mesmo tempo, esta estrutura de topo está também obrigada a prestar contas à comunidade local, através do Conselho Geral, que o seleciona e elege e que também o avalia (artigo 21 e seguintes).

\section{Escolaridade obrigatória}

A escolaridade obrigatória, de acordo com a Lei n. ${ }^{\circ} 85 / 2009$, de 27 de agosto, passou a decorrer ao longo de doze anos, repartida por quatro níveis de ensino $\left(1 .^{\circ}, 2 .^{\circ}\right.$ e $3 .^{\circ}$ ciclos e secundário). Ela abrange todas as 
crianças e jovens com idades compreendidas entre os seis e os 18 anos, incluindo aqueles que estão abrangidos pelo Decreto-Lei n. ${ }^{\circ}$ 3/2008, de 7 de janeiro.

O alargamento do ensino secundário a todos os alunos é também preconizado pela Unesco (2011) que o considera "um fator chave para melhorar o desenvolvimento social e o crescimento económicos" (p. 56). A própria Agência Europeia para o Desenvolvimento em Necessidades Educativas Especiais na Europa (2003) assume como uma das suas principais áreas de preocupação a inclusão dos alunos com NEE no ensino secundário.

No entanto, esta mesma entidade aponta quatro problemas para essa inclusão, desde a falta de recursos disponíveis, passando pela especificidade das disciplinas e pela diferente organização deste nível de ensino, até à distância entre os alunos com NEE e os seus pares, acentuada nestas idades. Por isso, a Agência supracitada alerta para a necessidade de formação inicial de professores, a fim de poderem trabalhar a "educação inclusiva" (2009), e para a necessidade de se proporcionar uma formação em serviço, a fim desenvolverem "conhecimentos e competências para melhorar a prática em contextos inclusivos" (p. 18), passando pela diferenciação de respostas às distintas necessidades, pelo trabalho colaborativo com pais e famílias e pela colaboração e trabalho em equipa.

Em suma, uma escolaridade obrigatória de doze anos é aconselhável e desejável, mas deverá ser uma decisão pensada, participada e assumida por todos, já que implica a "substituição de uma escola seletiva por uma escola que sabe acolher todos os alunos", cujas enormes alterações "não se compadecem com prazos curtos e muito menos se envolverem mudanças radicais de paradigma", como é o caso (Parecer n. ${ }^{\circ}$ 2/2012, do Conselho Nacional de Educação).

\section{Alunos com NEE}

Os alunos com NEE encontram-se, atualmente, abrangidos pelo Decreto-Lei n. ${ }^{\circ}$ 3/208, de 7 de janeiro, que prevê a criação de Escolas de Referência, Unidades de Ensino Estruturado e Unidades de Apoio Especializado. De acordo com este normativo legal e após a referenciação do aluno, o Diretor solicita ao Departamento de Educação Especial e aos Serviços de Psicologia e Orientação (SPO) um relatório TécnicoPedagógico. É então feita a avaliação do aluno, de acordo com a Classificação Internacional de Funcionalidade (CIF), tendo depois o Conselho Pedagógico e Diretor de aprovar o Programa Educativo Individual (PEI). 


\section{Cristina Rocha Matos e João Esteves Salgueiro}

Existem duas opções para os alunos com NEE. Se podem, com adequações no processo de ensino aprendizagem, adquirir as competências definidas no currículo, o PEI prevê, entre outras, a aplicação de adequações curriculares individuais. No ensino secundário, este aluno, terá a possibilidade de optar entre os cursos científico humanísticos e cursos profissionais. No caso de o aluno ter NEE que o impeçam de adquirir as aprendizagens e competências definidas no currículo, para além do PEI, terá um Plano Individual de Transição (PIT), com o objetivo de promover a transição para a vida pós escolar e para o exercício de uma atividade profissional, e um Currículo Educativo Individual (CEI), que irá substituir as competências definidas pelo currículo comum para cada um dos níveis de ensino. No ensino secundário, este aluno, será obrigado a matricular-se em cursos científico humanísticos (pois os cursos profissionais são subsidiados pelo POPHPrograma Operacional Potencial Humano- e permitem aos alunos uma dupla certificação: diploma de $12{ }^{\circ}$ ano e qualificação profissional de nível três, não alcançável pelos alunos com CEI, pelo que, o POPH, não procede ao seu financiamento).

De acordo com o Despacho Normativo n. ${ }^{\circ}$ 6/2012, de 10 de abril, apenas os alunos com CEI não realizam os exames nacionais de $9 .^{\circ}$ ano, a Português e Matemática. No ensino secundário todos os alunos com NEE, a frequentar cursos científico humanísticos, terão de realizar os respetivos exames nacionais, do $11 .^{\circ}$ e de $12 .^{\circ}$ anos, excluindo-se apenas aqueles que têm CEI.

É neste quadro que, na esteira de Kauffman (2003), também nós consideramos que "os professores e administradores têm a obrigação moral de reconhecer o facto de que muitos alunos de educação especial não deviam ser obrigados a realizar exames estatais de competências (p. 177), uma vez que muitos deles "necessitam de aprender coisas diferentes das do currículo-padrão e não unicamente aprender esse currículo de forma diferente ou num local diferente" (p. 188).

\subsection{Inclusão e Justiça Social}

\section{Conceito de inclusão}

"Inclusão opõe-se à exclusão; a normalização opõe-se à segregação; à institucionalização contrapõe-se a integração" (p. 198). É desta forma que Batista (2008) resume a História da Educação Especial.

O conceito de inclusão, introduzido pela Declaração de Salamanca sobre os Princípios, a Política e as Práticas na área das NEE, realizada entre 7 e 10 de junho de 1994 e organizada pelo governo espanhol, em cooperação com a Unesco, surge ligado à Educação Especial. Sendo um conceito polissémico e ambíguo que, parafraseando Roger Slee, "está a 
sofrer os efeitos de jetlag, está a perder a sua frescura e está a ter demasiadas interpretações" (cit. por Ainscow, EENET, 2004). Ainscow, Booth e Dyson (2006) definem inclusão como "uma abordagem à educação incorporando valores específicos. Preocupa-se, desta forma, com todos os alunos e com a superação de barreiras a todas as formas de exclusão, marginalização e insucesso" (p. 5).

A par da diversidade de definições que origina, o termo inclusão, coloca-nos perante os dilemas de diferença (Norwich, 2008), "situação em que existe uma escolha entre alternativas que são desfavoráveis" (p. 3). Esses dilemas situam-se em três áreas: a identificação (devemos ou não identificar uma criança ou um jovem como tendo dificuldades educativas acentuadas), o currículo (o currículo deverá ou não ser comum a todas as crianças e jovens) e a colocação (deverão todas as crianças e jovens ser colocados nas escolas e salas de aula regulares, ou não). Qualquer que seja a opção tomada, a dúvida e a incerteza quanto à sua validade permanecem $a b$ aeterno com quem a tomou e o peso dessa decisão pode ser muito difícil de suportar.

A questão da colocação de todos dos alunos com NEE nas escolas de ensino regular tem sido muito debatida. O movimento da 'full inclusion', que começou a ser defendido nos anos 80 , bate-se pela colocação de todos os alunos, independentemente da gravidade da sua deficiência, nas escolas regulares, levando ao encerramento das escolas de Ensino Especial. Alguns dos defensores desta posição, que apenas têm em linha de conta o desenvolvimento social e a participação dos alunos com NEE, são Susan e William Stainback (Correia, 2003, p. 15).

Contra a inclusão total estão os que defendem a "hipótese de escolha" (Liberman, 2003, p. 92). Não por estarem a favor da exclusão, mas porque "o conceito de inclusão total implica que isto seja verdade [ver todos os alunos como indivíduos únicos e completos] em classes regulares (...) o que, muito provavelmente, corresponde ao oposto daquilo que é a realidade" (Liberman, 2003, p. 93). Esta mesma posição tem a Unesco (2005), quando afirma que nos casos em que o ensino regular "não garante uma significativa interação entre alunos e profissionais" (p. 27), pode ser mais benéfico o seu encaminhamento para escolas especiais. A própria Mary Warnock, responsável pelo relatório que esteve na origem da mudança da Educação Especial, manifesta o seu desacordo em relação à "full inclusion".

\section{Justiça social}

O conceito de educação inclusiva insere-se no contexto da inclusão social e incorpora o de justiça social. De acordo com Estêvão (2002), "o conceito de justiça articula-se em qualquer democracia com outros 


\section{Cristina Rocha Matos e João Esteves Salgueiro}

conceitos, como o de igualdade, de equidade, de liberdade, de mérito, de poder e autoridade, que vão condicionar também o modo como pensamos a educação e o modo como as escolas devem organizar-se para cumprirem as suas finalidades" (p.117).

Usada pela primeira vez pelo jesuíta italiano Louis Taparelli d'Azeglio, em 1840, a expressão 'justiça social', tem sido empregue com frequência e com várias aceções. Atualmente existem, de acordo com Torrecilla e Castilla (2011), três grandes conceções de justiça social: como distribuição (de bens, recursos naturais e culturais e capacidades), como reconhecimento (reconhecimento e respeito por todas as pessoas, existência de relações justas na sociedade) e como participação (participação nas decisões que afetam as suas vidas). $\mathrm{O}$ direito a um ensino de qualidade, por parte dos alunos com NEE é, de acordo com estas conceções, uma questão de justiça social. Estes alunos têm direito a ofertas educativas adequadas às suas capacidades e interesses; ao respeito por parte da sociedade; e a participar em todas as decisões que afetam, direta ou indiretamente, as suas vidas.

\section{ESTUDO EMPÍRICO}

\subsection{Metodologia}

A problemática escolhida para esta investigação consistiu em procurar descortinar o papel das estruturas de gestão intermédia na inclusão dos alunos com NEE no ensino secundário. A partir deste problema inicial foram elaboradas três questões centrais (Quadro III), "a partir das quais se pode organizar solidamente o programa de pesquisa, com a clarificação do âmbito da investigação" (Afonso, 2005, p. 53).

\section{Quadro III}

Questões centrais

1. ${ }^{\mathrm{a}}$ Como é que os gestores intermédios percecionam o seu papel no acolhimento e sucesso dos alunos com NEE e que medidas consideram ser prioritárias para proporcionar o êxito da integração dos alunos com NEE no ensino secundário?

2. ${ }^{\text {a }}$ Quais os constrangimentos e/ou potencialidades para o desenvolvimento de práticas de gestão curricular intermédia orientadas para o sucesso da educação inclusiva?

3. ${ }^{\text {a }}$ Em que medida são desenvolvidas políticas educativas locais coerentes e articuladas orientadas para o desenvolvimento de práticas de educação inclusiva? ${ }^{3}$

\footnotetext{
${ }^{3}$ Dadas as limitações de tempo e a temática escolhida estar focada nas estruturas de gestão intermédia, esta questão teve um tratamento limitado ao ponto de vista dos líderes escolares.
} 
Estabelecemos depois, o objetivo geral e os objetivos específicos para obtermos as respostas às questões centrais (Quadro IV).

\section{Quadro IV}

Objetivos

\section{Objetivo geral:}

- Percecionar o papel das estruturas intermédias na definição e desenvolvimento de políticas e práticas educativas locais orientadas para a inclusão de alunos com NEE no ensino secundário.

\section{Objetivos específicos:}

- Clarificar a existência de referenciais de Inclusão preconizados no Projeto Educativo do Agrupamento e nas representações dos líderes intermédios.

- Identificar as principais barreiras à inclusão dos alunos com NEE no ensino secundário, percecionadas pelos líderes intermédios.

- Conhecer as possíveis ofertas educativas que estão a ser pensadas para os alunos com NEE que vão iniciar $10^{\circ}$ ano.

- Abordar a forma como está a ser feita a preparação dos professores do ensino secundário para receber e trabalhar com os alunos com NEE.

- Sentir o contributo das estruturas de gestão intermédia para o sucesso do processo de inclusão.

- Refletir sobre a forma como está a ser feita a coordenação entre as várias estruturas de gestão intermédia, a gestão de topo, os alunos e os pais com vista à criação de condições facilitadoras da inclusão dos alunos com NEE, no $10^{\circ}$ ano, e à conclusão da escolaridade obrigatória de 12 anos com sucesso.

Neste estudo foi utilizada a investigação de tipo qualitativo "cuja finalidade é compreender um fenómeno segundo a perspetiva dos sujeitos; as observações são descritas principalmente sob a forma narrativa" (Fortin, 2009, p. 371). Deste tipo de investigação destacamos a perspetiva naturalista, o estudo descritivo e a importância atribuída, não aos dados quantitativos mas, à compreensão do processo e ao fenómeno em si. Como método de colheita de dados optámos pela entrevista semiestruturada, baseada em sete dimensões (Quadro V), realizada presencialmente, com recurso a um guião, previamente elaborado. 


\section{Quadro V}

Dimensões das entrevistas aos líderes e respetivas dimensões

\begin{tabular}{|c|c|}
\hline Dimensões & Objetivos \\
\hline $\begin{array}{l}\text { A- Questões de } \\
\text { enquadramento }\end{array}$ & $\begin{array}{l}\text { Tentar perceber se, na opinião das lideranças, a } \\
\text { situação do alargamento da escolaridade obrigatória } \\
\text { para } 12 \text { anos, também para os alunos com NEE, } \\
\text { constitui uma preocupação dos professores }\end{array}$ \\
\hline $\begin{array}{l}\text { B- expectativas dos } \\
\text { professores }\end{array}$ & $\begin{array}{l}\text { Identificar os receios dos professores do ensino } \\
\text { secundário, percecionados pelas lideranças, } \\
\text { relativamente à inclusão dos alunos com NEE nas } \\
\text { turmas. }\end{array}$ \\
\hline $\begin{array}{l}\text { C- Práticas } \\
\text { inclusivas }\end{array}$ & $\begin{array}{l}\text { Determinar o conceito de inclusão promovido pelo } \\
\text { agrupamento e sentido pelas lideranças. }\end{array}$ \\
\hline $\begin{array}{l}\text { D- Preparação dos } \\
\text { alunos com NEE }\end{array}$ & Percecionar a posição das lideranças face à inclusão \\
\hline $\begin{array}{l}\text { E- Quadro } \\
\text { normativo }\end{array}$ & $\begin{array}{l}\text { Saber qual a opinião das lideranças em relação à } \\
\text { legislação em vigor que regula as NEE }\end{array}$ \\
\hline $\begin{array}{l}\text { F- Trabalho direto } \\
\text { com alunos com } \\
\text { NEE }\end{array}$ & $\begin{array}{l}\text { Perceber qual a predisposição dos líderes intermédios } \\
\text { e dos professores que coordenam para trabalharem } \\
\text { com alunos com NEE }\end{array}$ \\
\hline G- Lideranças & $\begin{array}{l}\text { Determinar o peso das lideranças intermédias e a sua } \\
\text { capacidade de iniciativa para promover a inclusão }\end{array}$ \\
\hline
\end{tabular}

Associada à entrevista foi também utilizada a pesquisa documental, com análise do Regulamento Interno do Agrupamento, do Projeto Educativo das escolas agrupadas e do Plano Anual de Atividades.

$\mathrm{O}$ critério de seleção da população alvo, "aquela que o investigador quer estudar" (Fortin, 2009, p.41), foi determinado pela "relação íntima dos participantes com a experiência que se quer descrever e analisar" (Fortin, 2009, p. 149). Falamos das lideranças intermédias: Coordenadores de Departamento Curricular; Coordenadores de Diretores de Turma; Coordenadores de Estabelecimento; líderes informais e responsável pelos Serviços de Psicologia e Orientação. Por convicção nossa, incluímos também neste estudo o Diretor e o Presidente do Conselho Geral. Esta opção justifica-se pela dualidade de papéis que, em nossa opinião, ambos têm na organização escolar. Se a nível do agrupamento, e através de uma análise meso, ambos são gestores de topo, a nível nacional, numa macro análise, são os intermediários entre o poder central e as estruturas de coordenação educativa do agrupamento. Desta forma, entendemos que o estudo deveria ter como população acessível, a "população alvo que está ao alcance do investigador" (Fortin, 2009, p. 41), perfazendo um total de treze sujeitos entrevistados. 
A fidelidade e validação dos resultados foram garantidas pela supervisão do orientador, pelo uso dos 'casos negativos' (entrevista aos líderes informais, responsável pelos SPO, Diretor e Presidente do Conselho Geral) e pela triangulação de dados fornecida pelos documentos oficiais do agrupamento.

Das 13 entrevistas, 11 foram gravadas e, todas elas, transcritas na íntegra. Posteriormente foram construídas grelhas de análise, sendo os dados codificados e, só depois, iniciada a interpretação dos mesmos, à luz do quadro teórico previamente estabelecido.

\subsection{Apresentação dos resultados}

As principais preocupações das lideranças, no que respeita ao alargamento da escolaridade obrigatória, também para os alunos com NEE, centram-se:

1. ${ }^{\circ}$ No contexto de sala de aula, onde os alunos não conseguem "acompanhar o currículo" E8, necessitando de "um apoio mais especializado" E2, podendo "ser um entrave, entre aspas, ao trabalho que nós pretendemos desenvolver com os outros" E10; tendo em conta "(...) questões de trabalho dos colegas que não estão habituados a lidar com este tipo de alunos" E12.

2. Ao nível da avaliação, alguns dos sujeitos, questionaram: "como é que se vai fazer com as disciplinas de exame nacional?" E5, até porque, acrescenta outro, "no ensino secundário a nossa preocupação fundamental é preparar os alunos para os exames e muitas vezes nós não temos a disponibilidade mental para estar em simultâneo a prestar um apoio mais individualizado com alunos que estão nitidamente... têm nitidamente... mais dificuldades que os outros" E10

3. Quanto à escassez de oferta educativa para responder às necessidades dos "alunos com NEE do domínio cognitivo" E13, pois, como se considera, "a escola tem pouco para oferecer" E6; para além disso, também é manifesta a "falta de recursos adequados à idade deles" E9.

Através de um questionário levado a cabo pelos SPO, e que foi dirigido a todos os alunos do $9 .^{\circ}$ ano, foram diagnosticados os interesses relativamente à oferta educativa e $62 \%$ dos alunos com NEE indicaram a sua preferência por cursos profissionais. Nesta auscultação não foram 


\section{Cristina Rocha Matos e João Esteves Salgueiro}

ouvidos os alunos com CEI, uma vez que estes "têm de estar matriculados numa turma onde estejam o máximo tempo possível com os colegas" E6.

As lideranças têm a perceção que os professores não se sentem preparados para trabalhar com os alunos com NEE, no ensino secundário, por razões que vão desde o facto de os alunos não conseguirem acompanhar as matérias, até a um maior distanciamento entre professores e alunos, neste nível de ensino, incluindo a falta de preparação, a falta de ajuda diretiva e as especificidades do ensino secundário.

As barreiras à inclusão, identificadas pelos líderes, passam pela dificuldade de trabalhar com os alunos com NEE, em contexto de sala de aula, até pela falta de formação de professores; pela falta de recursos materiais e humanos (barreiras arquitetónicas, que ainda existem, falta de equipamento e de técnicos especializados e de ofertas educativas). A pouca clareza da legislação em vigor e as mentalidades (piedade, caráter seletivo do ensino secundário e dos professores, falta de trabalho por parte dos alunos com NEE, após a sua identificação, falta de dinamismo da organização educativa), assim como a referência ao excesso de burocracia, são outros tipos de barreiras enumeradas pelos entrevistados. Como potencialidades, os entrevistados, identificaram a participação e empenho da Câmara Municipal e da comunidade local; a existência da Unidade de Multideficiência e de Surdo Cegueira Congénita; o apoio por parte do Diretor; as parcerias com outras entidades; o envolvimento da comunidade educativa; a continuidade entre ciclos $\left(3 .^{\circ}\right.$ ciclo e secundário) e a partilha de experiências.

Com efeito, o envolvimento da Câmara Municipal na operacionalização do paradigma de inclusão é percecionado, de forma bastante positiva, pelas lideranças. Consideram mesmo que o poder local contribui para a eliminação de barreiras arquitetónicas no concelho, disponibiliza transportes e instalações desportivas, dá formação a professores, apoia o funcionamento da Unidade de Multideficiência e Surdo Cegueira Congénita, que ajudou a criar, e preocupa-se com a inserção dos alunos com CEI na vida ativa.

No que respeita à inclusão total, as perceções das lideranças vão no sentido de incluir, sim, mas se houver condições por parte da escola e se a criança ou jovem conseguir interagir, caso contrário deverá ser encaminhado para uma Escola Especial, uma vez que há casos em que " $a$ escola não tem essa capacidade, porque isso aí, já era quase estar a fazer atos de acompanhamento médico” E12.

Segundo os sujeitos entrevistados, o perfil de um líder intermédio passa por quatro competências essenciais: dominar relações pessoais; demonstrar capacidade de liderança; dominar a legislação e saber gerir conflitos. Consideram que existe o reconhecimento pessoal e coletivo dos 
cargos de liderança intermédia, que determinam o sucesso ao nível superior. Para os entrevistados, "o topo só funciona se as estruturas intermédias funcionarem bem" E1. Para além disso, são eles que motivam "os colegas para fazer um trabalho colaborativo" E2. É também notória a importância que atribuem à promoção do sucesso dos alunos com NEE, por "darem prosseguimento às orientações do Diretor" E3, "transmitirem a filosofia da escola aos colegas" E13, prestarem "um apoio mais próximo e efetivo" E4 aos alunos com NEE e determinarem a participação das pessoas, ao "motivá-las e envolvê-las" E3.

Contudo, mais de $70 \%$ dos líderes intermédios referem que não estabeleceram nenhum contacto com os pais dos alunos com NEE, a fim de tentarem percecionar as suas preocupações quanto ao alargamento da escolaridade obrigatória. $88 \%$ desses líderes não desenvolveu, até esse momento, nem estava a pensar desenvolver, quaisquer atividades no sentido de preparar os professores do departamento curricular para o alargamento da escolaridade obrigatória. $75 \%$, também não estabeleceu contactos com outros coordenadores, com o Diretor ou o poder local acerca do assunto.

\subsection{Discussão dos resultados}

A partir dos dados recolhidos, não só através das entrevistas mas também dos documentos oficiais do agrupamento, iremos, neste contexto, apresentar dez das conclusões a que chegámos.

1. Existem diferenças de entendimento e de operacionalização do conceito de inclusão entre as escolas básicas e a escola secundária. Essas diferenças são notórias, por exemplo, nos Projetos Educativos. Estas diferenças têm, talvez, justificação no facto de as escolas básicas acolherem os alunos com NEE há mais de duas décadas, o que não acontecia nas escolas secundárias que não eram frequentadas por este tipo de alunos.

2. Verifica-se a consciência da necessidade de formação de professores na área das NEE e, muito em particular, sobre a forma de prestar apoio individualizado em contexto de sala de aula, problemática reconhecida pela Agência Europeia para o Desenvolvimento da Educação Especial (2009).

3. Aos professores colocam-se, tal como enunciava Norwich (2008), dilemas educativos que os deixam angustiados. O dilema da identificação, porque há pais que "dizem que é por estarem incluídos na lei 3 que eles fazem menos, porque se lhes pede menos" E8. O dilema do currículo e das adequações curriculares, que os professores afirmam não saber como fazer: "muitas vezes a adequação curricular acaba por ser 
uma simplificação, ou seja, acabamos por retirar conteúdos e não os ajustamos efetivamente" E10, sendo "muito dificil, nós, decidirmos o que vamos exigira a este aluno" E10. O dilema da colocação, uma vez que "os alunos, com deficiências muito graves, teriam maior rendimento em escolas específicas. Aqui não se desenvolvem como deveriam, pelo menos nestas disciplinas mais teóricas que frequentam. Mas ganham na integração..." E2.

4. As lideranças intermédias têm um potencial enorme e desempenham um papel decisivo na organização escolar, rumo à inclusão. O "papel híbrido" de que falava Blanford (2008), de professores, líderes e membros da equipa, coloca-os na posição ideal para veicularem a filosofia do agrupamento e para prestarem uma ajuda diretiva aos colegas. No entanto, e apesar da consciência desse seu papel e da sua importância para o sucesso dos alunos com NEE, eles não assumem, junto dos seus liderados, uma posição proactiva e dinâmica. Revelam, antes, uma apatia e uma falta de vontade interventiva a nível central e a nível de estabelecimento de ensino, face a um assunto que, como afirmam, os preocupa.

5. Tal como Bateman e Snell (2008), também os nossos sujeitos identificam como competências básicas para um perfil de coordenador: as competências técnicas "a primeira coisa é saber os normativos legais e depois saber aplicá-los" E3; as competências interpessoais e de comunicação, "essa parte das relações interpessoais" E5; competências conceptuais e decisórias: "têm que ter poder de decisão" E6.

6. Os nossos sujeitos consideram, tal como Chiavenato (2004), que os líderes deverão combinar os vários estilos de liderança, de acordo com as situações. "O líder tem de fazer valer as suas ideias" E10 - o elemento autoritário, mas tem de "ser democrata, o mais possivel, não estar a impor" E11- o elemento democrático.

7. As três grandes conceções de justiça social, preconizadas por Torrecilla e Castilla (2011), não estão ao dispor dos alunos com NEE. Vejamos: a justiça como distribuição não existe, uma vez que as escolas não lhe disponibilizam os recursos necessários; a justiça enquanto reconhecimento é-lhes negada, desde logo, pelo próprio Ministério da Educação e da Ciência, que não estabelece com eles uma relação justa e com respeito pela diferença, obrigando-os a realizar exames a nível nacional; a justiça enquanto participação é atropelada pelo alargamento da escolaridade obrigatória que os limita, ou impede, de participar nas decisões que estão diretamente relacionadas com o seu futuro, por exemplo, ao impor a obrigatoriedade dos alunos com CEI se inscreverem em cursos científico humanísticos e, aos alunos com NEE do domínio cognitivo, de realizarem exames nacionais de $11 .^{\circ}$ e $12 .^{\circ}$ anos para obterem o diploma. 
8. Os exames são o el dorado da educação atual, "educação contábil" Lima (2005), onde a "preocupação fundamental é preparar os alunos para os exames" E10. Como tão bem colocou um dos nossos sujeitos, "o que é que no fundo a sociedade exige de nós? $E$ (...) o sucesso dos alunos, mas um sucesso académico, são as notas, e isto aqui não vem nas notas, há aqui situações de alunos [para os quais] o sucesso é um bocado os miúdos integrarem-se na sociedade, aprenderem a fazer coisas práticas e não tanto o sucesso académico, enquanto a maioria dos professores- e falo por mim-, nós preocupamo-nos muito mais com o sucesso, é o sucesso, é o sucesso..." E7.

9. Os sujeitos entrevistados são adeptos da inclusão parcial ou moderada, ao considerarem que "há situações extremas que, se calhar, [mostram que] não, os alunos não têm o melhor nas escolas regulares" E4. As suas opiniões são condicentes com a posição da Unesco (2005) que considera que o "encaminhamento para escolas especiais de elevada qualidade" (p. 27) é o mais apropriado para o aluno que não interage. Sem condições para receber estes alunos a "escola vira um gueto (...) o aluno está ali, o aluno foi à escola, mas ele está na escola?” E6.

$10 .^{\circ} \mathrm{O}$ poder local desenvolve uma série diversificada de medidas educativas locais em prol da inclusão dos alunos com NEE do concelho, trabalhando em parceria com o agrupamento e estando disponível para escutar, participar e partilhar da sua filosofia de inclusão.

\section{CONCLUSÃO}

O método de recolha de dados revelou-se o mais adequado ao tipo de investigação levada a cabo. No entanto, a amostra foi, talvez, demasiado grande, tendo em linha de conta o enorme manancial de informação gerada pelas entrevistas e o tratamento das mesmas sem recurso a programas específicos.

Face à entrada eminente de um novo público, 'não alvo', na escola secundária seria de supor que as lideranças intermédias estivessem a envidar todos os esforços para preparar os seus liderados para o trabalho com os alunos com NEE, o que não se verificou. A entrada destes alunos não foi devidamente assegurada pelo poder central, ao não proporcionar ofertas educativas eficazes e direcionadas para estes novos 'utilizadores', nem pela organização educativa, ao não promover o debate interno e a busca de soluções, quer para o sucesso educativo dos alunos com NEE quer para acalmar e esclarecer os professores do ensino secundário que iriam trabalhar com eles.

$\mathrm{Na}$ nossa ótica, seria pertinente levar a efeito, no final do ano letivo em curso, um balanço do $1 .^{\circ}$ ano de aplicação da nova lei da escolaridade 


\section{Cristina Rocha Matos e João Esteves Salgueiro}

obrigatória. Dos 17 alunos que frequentam a escola secundária, quais os que estão nos cursos desejados? Qual a verdadeira integração dos alunos com CEI, inseridos numa turma onde não têm nenhuma aula em conjunto com os restantes colegas (pois, como não existe a disciplina de Formação Cívica, muitas turmas não estão inscritas em Educação Moral e Religiosa Católica e os alunos não podem praticar Educação Física com os colegas). Quais os benefícios que estes alunos retiraram, até agora, do alargamento da escolaridade obrigatória?

\section{REFERÊNCIAS BIBLIOGRÁFICAS}

Afonso, Natércia (2005). Investigação Naturalista em Educação - Um guia prático e crítico. Lisboa: ASA.

Agência Europeia para o Desenvolvimento da Educação Especial (2003). Necessidades Educativas Especiais na Europa. Acedido em http://www.european-agency.org/publications/ereports/specialneeds-education-in-europe/sne_europe_pt.pdf/at_download/file.

Agência Europeia para o Desenvolvimento da Educação Especial (2009). Princípios-Chave para a Promoção da Qualidade na Educação Inclusiva Recomendações para Decisores Políticos. Acedido em http://www.european-agency.org/publications/ereports/keyprinciples-for-promoting-quality-in-inclusive-education/keyprinciples-PT.pdf.

Ainscow, Mel, Booth, Tony, Dyson, Alan (2006). Improoving Schools, Developing Inclusion. Oxon: Routlege.

Batista, José Afonso (2008). Os surdos na escola. Vila Nova de Gaia: Fundação Manuel Leão.

Bateman, Thomas, Snell, Scott (2008). Management Leading \& Collaborating, in a Competitive World. 8. Edição. Boston: McGrawHills/Irwin.

Blandford, Sonia (2006). Middle Leadership in Schools: Harmonising Leadership and Learning. 2.nd ed. UK: Pearson Education Limited.

Chiavenato, Idalberto (2004). Introdução à Teoria Geral da Administração. 7. ${ }^{\text {a }}$ ed. Rio de Janeiro: Elsevier Editora.

EEENET (2004). Enabling Education (8) Edição Especial: SalamancaDez anos depois. Acedido em http://www.eenet.org.uk/resources/docs/eenet_news8_por.pdf.

English, Fenwick W. (2006). Encyclopedia of Education Leadership and Administration. California: SAGE Publications. Vol. 2.

Estêvão, Carlos Alberto Vilar (2002). Justiça complexa e educação. Uma reflexão sobre a dialetologia da justiça em educação. Revista Crítica de Ciências Sociais, 64. pp. 107-134. 
Fortin, Marie-Fabienne (2009). O Processo de Investigação: da conceção à realização. 5. Edição. Loures: Lusociência.

Kauffman, James M. (2003). Conferir coerência à educação. In Correia (Org), Educação Especial e Inclusão Quem Disser Que Uma Sobrevive Sem a Outra Não Está no Seu Perfeito Juízo. Porto: Porto Editora, pp 156-205.

Libâneo, José Carlos (2001). Organização e Gestão da Escola - Teoria e Prática. 4. ${ }^{a}$ ed. Goiânia: Editora Alternativa.

Lieberman, Laurence (2003). Preservar a educação especial... para aqueles que dela necessitam. In Correia (Org), Educação Especial e Inclusão Quem Disser Que Uma Sobrevive Sem a Outra Não Está no Seu Perfeito Juizo. Porto: Porto Editora, pp 90-107.

Lima, Licínio C. (2005). Cidadania e Educação: Adaptação ao mercado competitivo ou participação na democratização de democracia?. Educação, Sociedade e Culturas, n. . 22. pp. 71-90.

Northouse, Peter G. (2010). Leadership theory and practice. 5th ed. California: SAGE Publications, Inc.

Maxwell, John C. (2011). The $360^{\circ}$ leader developing your influence from anywhere. In the organization. Tennesse: Thomas Nelson, Inc.

Morgan, Gareth (2006). Imagens da organização. 2. ${ }^{a}$ Edição. S.Paulo: Editora Atlas SA.

Norwich, Brahm (2008). Dilemas of Difference, Inclusion and Disability, Internacional

Perspetives and Future Directions. Oxon: Routledge.

Radcliffe, Steve (2010). Leadership Plain and Simple. Great Britain: Pearson Education

Smith, Alistair (2011). High Performers: The Secret of Successful Schools. UK: Crown House Publishing Ltd.

Torrecilla, F. Javier Murillo, Castilla, Reys Hernández (2011). Hacia un Concepto de Justicia Social. Revista Iberoamericana sobre Calidad, Eficacia y Cambio en Educación, Vol. 9, n. ${ }^{\circ} 4$. pp.8-23.

UNESCO (2005). Orientações para a Inclusão Garantindo o Acesso à Educação para Todos. Acedido em http://bippsp.bipp.pt/documentos/educacao/Documentos/Orientações \%20para\%20a\%20Inclusão\%20-\%20UNESCO.pdf.

UNESCO (2011). Global Education Digest 2011, comparing education statistics across the world. Acedido em http://www.uis.unesco.org/Library/Documents/global_education_dig est_2011_en.pdf. 


\section{REFERÊNCIAS NORMATIVAS}

Lei n. ${ }^{\circ} 85 / 2009$, de 27 de agosto;

Decreto-Lei n. ${ }^{\circ} 3 / 2008$, de 7 de janeiro;

Decreto-Lei n. ${ }^{\circ}$ 75/ 2008, de 22 de abril;

Decreto-Lei n. ${ }^{\circ}$ 137/ 2012, de 2 de julho;

Despacho Normativo n. ${ }^{\circ}$ 6/2012, de 10 de abril;

Parecer n. ${ }^{\circ}$ 2/2012, do Conselho Nacional de Educação. 